\title{
Analysis of the Promoter Hypermethylation of Chosen Tumor Suppressor Genes in Laryngeal Cancer
} \author{
David $^{3}$, Pitala Grzegorz ${ }^{4}$, Maciejczyk Adam ${ }^{5}$ and Sasiadek M Maria ${ }^{1}$ \\ ${ }^{1}$ Department of Genetics, Wroclaw Medical University, Poland \\ ${ }^{2}$ Department of Otolaryngology, Wroclaw Medical University, Poland \\ ${ }^{3}$ Faculty of Computer Science and Management, Wroclaw University of Technology, Poland \\ ${ }^{4}$ Department of Clinical Otolaryngology, $4^{\text {th }}$ Military Hospital, Poland \\ ${ }^{5}$ Lower Silesian Oncology Center Wroclaw, Poland
}

Stembalska Agnieszka ${ }^{1}$, Gil Justyna ${ }^{1}$, Laczmanska Izabela ${ }^{1}$, Fraczek Marcin ${ }^{2}$, Czykalko Ewelina ${ }^{1}$, Ramsey

Submission: January 18, 2018; Published: February 16, 2018

*Corresponding author: Agnieszka Stembalska, Department of Genetics, Wroclaw Medical University, Marcinkowskiego 1, 50-367 Wroclaw, Poland; tel. +48-71-784-12-56, fax: +48-71-784-00-63, Email: stembalska8@gmail.com

\begin{abstract}
Background: DNA hypermethylation is one of the epigenetic mechanisms leading to transcriptional inactivation of genes and shows tissue and tumor-type specificity.

Methods: We evaluated DNA deletions/duplications as well as hypermethylation status of chosen tumor suppressors in 57 laryngeal squamous cell carcinomas using MS-MLPA.

Results: We observed a significantly higher frequency of gene methylation and deletions in cancer cells compared to normal laryngeal cells. In tumor cells, hypermethylation is also often observed at ESR1 and CDH13, TIMP3, RARB, while CDKN2B hypermethylation appears to be increased in both normal and tumor cells. Deletions suggest the presence of genetic instability in LSCC and in tumors are associated with low values of tumor size and stage. The risk of metastases increased with at least 3 deletions in the laryngeal tumor, in particular with deletion at the FHIT locus, also with at least 3 hypermethylated sites in normal laryngeal cells.
\end{abstract}

Conclusion: The results of our study confirm involvement of both epigenetic and genetic events in laryngeal cancer development.

Keywords : MS-MLPA; Laryngeal cancer; Promotor methylation; Suppressor gene

\section{Introduction}

Laryngeal cancer (in 95\% - LSCCs, laryngeal squamous cell carcinomas), an uncommon type of cancer, belongs to the subgroup of head and neck cancers (HNSCCs, head and neck squamous cell carcinomas) [1]. On average, around 2800 new cases of laryngeal cancer are diagnosed each year in Poland $[2,3]$. LSCC is relatively rare in people under the age of 40 , mainly affect people in their 60s and 70s. Laryngeal cancer is much more common in men than in women. The incidence ratio for males compared to females ranges from around 1:1 to $80: 1$, depending on the country and even specific regions within countries $[4,5]$ The most common location of laryngeal cancer is the glottis (in Poland - over 47\% laryngeal cancers) [6]. Cancers in the supraglottis are much more frequently observed in women [5].
The aetiology of laryngeal cancer is complex, influenced by genetic and epigenetic alterations, as well as exposure to carcinogens. Tobacco and alcohol are known environmental risk factors, metabolites of which may contribute to DNA damage. Moreover, genetic variants in some genes acting in both xenobiotic metabolism and DNA repair pathways may affect an individual's susceptibility to LSCC. CpG island hypermethylation within promoter regions of tumor suppressor genes is the one of the important epigenetic mechanisms leading to transcriptional inactivation of genes and shows tissue and tumor-type specificity [7].

In this study, we evaluated the promotor methylation status of chosen tumor suppressor genes in LSCC within a Polish cohort using MS-MLPA assay (methylation-specific multiplex ligationdependent probe amplification). 


\section{Global Journal of Otolaryngology}

\section{Material}

The study was performed on DNA isolated from histopathologically confirmed laryngeal cancer tissues and adjacent normal laryngeal tissues. Tissue samples were obtained from a homogeneous group of 57 patients (a part of a previously described group) with primary LSCC $[8,9]$. All the 57 patients were Caucasians from Lower Silesia province in Poland. All tissue samples from the study group were taken during laryngectomy. The patients had no prior chemotherapy or radiotherapy. The study received approval from the Bioethics Committee of Wroclaw Medical University (KB-332/2006).

The mean age of the patients was 60.1 years (range 43-80). The median follow-up time was 29.4 months (range 5 to 172 months). None of the patients had distant metastases at the time of diagnosis. During follow-up, 6 patients developed distant metastases (10.5\%) and 15 patients $(26.3 \%)$ were found to have recurrences of LSCC. Of the 57 patients, 21 patients died $(36.8 \%)$, with the average age at death being 60.3 years.

\section{Methods}

Screening for promoter methylation and exon deletion/ duplication was performed using SALSA MLPA ME001 Tumor Suppressor Mix 1 (MRC-Holland, Amsterdam, The Netherlands). This kit contains 26 MS-MLPA probes analyzing the methylation status of the promoter region of 24 different tumor suppressor genes. Described group of 57 patients was a part of the group of 72 patients with LSCC in which the analysis of CpG island hypermethylation (tumor suppressor genes: CDKN2A (p16), p14 ARF , CDKN2B (p15), TP73, TIMP3, APC, DAPK1, RARB2, GSTP1, RASSF1, CDH1, CASP8, hMLH1, MGMT, DCC, THBS1, TERT and the sequences MINT: MINT1, MINT2, MINT12, MINT25, MINT27, MINT31) using MS-PCR (methylation-specific polymerase chain reaction) method were previously performed [published in Polish] [9]. The MS-MLPA commercially available panel included eleven of those genes and one member of the cadherin superfamily - CDH13 (in MS-PCR is CDH1).

Genomic DNA was isolated from freshly-frozen solid tissues using a Gentra Puregene Tissue Kit (QIAGEN, Hilden, Germany) according to the producer's protocol. The producer's protocol for MS-MLPA, was applied precisely. The PCR products were separated using an ABI 310 Genetic Analyser in conjunction with GeneScan Analysis software version 3.1.2, POP-4 Polymer and the LIZ 500 size standard (Applied Biosystems, Foster City, USA). The analysis of the results was prepared using GeneMarker software version 1.85 (SoftGenetics LLC, USA).

With regard to the analysis of copy number variants, a change in the peak values of over +/-0.3 was considered as duplication (increase in value) or a deletion (decrease in value). To analyze promoter methylation, MS-MLPA analysis function was used. Probes with a ratio of over 0.3 were considered to be methylated (not digested by endonuclease).

\section{Statistical analysis}

The Mann-Whitney test and Kruskal-Wallis test were used to test for a difference between the means for two groups and several groups, respectively. The Cox-Mantel test and Wald's test were used to compare survival times. Fisher's exact test was used to analyze the association between two categorical variables and the Mantel-Haenzel test was used when the variables involved were ordinal. The 18th version of PASW was used.

\section{Results}

We observed a significantly higher frequency of gene methylation in cancer cells compared to normal laryngeal cells $(\mathrm{p}<0.001$, Fisher's test of independence; Table 1). In both tissues, the frequency of DNA methylation was significantly higher for the CDKN2B ( $\mathrm{p} 15)$ gene than the mean overall rate ( $\mathrm{p}<0.001$, test for a difference between two proportions) and tended to appear simultaneously ( $p=0.0003765$, Fisher's test of independence). Hypermethylation of the promoter region of TIMP3 was significantly more frequent in cancer than in normal tissue ( $p=0.029$, Fisher's test of independence). In cancer cells, hypermethylation tends to appear simultaneously at each of the following pairs of genes: APC/DAPK1 ( $p=0.0001661$; Fisher's test of independence), ATM/HIC1 ( $p=0.0006266)$, CD44/IGSF4 $\quad(p=0.0003418), \quad$ FHIT/IGSF $\quad(p=0.0003418)$, FHIT/MLH1 ( $p=0.0001443)$, IGSF4/MLH1 $\quad(p=0.00001266)$. In normal laryngeal cells, hypermethylation tends to appear simultaneously at the following pairs of genes: DAPK1/IGSF4 $(\mathrm{p}=0.0003418$, Fisher's test of independence), DAPK1/GSTP1 $(\mathrm{p}=0.0006835)$, IGSF4/GSTP1 ( $\mathrm{p}=0.0001841)$.

Table 1: Results of MS-MLPA analysis in 57 patients with laryngeal cancer.

\begin{tabular}{|c|c|c|c|c|c|c|}
\hline \multicolumn{3}{|c|}{ Hypermethylation } & \multirow{2}{*}{$\begin{array}{c}\text { Duplications } \\
\text { Cancer tissue } \\
(\%)\end{array}$} & \multicolumn{3}{|c|}{ Deletions } \\
\hline Gene & $\begin{array}{c}\text { Cancer tissue } \\
(\%)\end{array}$ & $\begin{array}{c}\text { Normal tissue } \\
(\%)\end{array}$ & & $\begin{array}{c}\text { Normal tissue } \\
(\%)\end{array}$ & $\begin{array}{c}\text { Cancer tissue } \\
(\%)\end{array}$ & $\begin{array}{c}\text { Normal tissue } \\
(\%)\end{array}$ \\
\hline TIMP3 & $10(17.5)$ & $2(3.5)$ & $4(7.0)$ & $4(7.0)$ & $2(3.5)$ & $4(7.0)$ \\
\hline APC & $9(15.8)$ & $3(5.3)$ & $1(1.8)$ & $3(5.3)$ & $6(10.5)$ & $2(3.5)$ \\
\hline CDKN2A & $3(5.3)$ & $0(0.0)$ & $4(7.0)$ & $9(15.8)$ & 7 (12.3) & $2(3.5)$ \\
\hline MLH1 & $5(8.8)$ & $2(3.5)$ & $16(28.0)$ & $14(24.6)$ & $17(29.8)$ & $6(10.5)$ \\
\hline ATM & $2(3.5)$ & $0(0.0)$ & $8(14.0)$ & $6(10.5)$ & $1(1.8)$ & $1(1.8)$ \\
\hline RARB & $8(14.0)$ & $2(3.5)$ & $5(8.8)$ & $2(3.5)$ & $8(14.0)$ & $2(3.5)$ \\
\hline
\end{tabular}


Global Journal of Otolaryngology

\begin{tabular}{|c|c|c|c|c|c|c|}
\hline CDKN2B & $40(70.0)$ & $33(57.9)$ & $0(0.0)$ & $5(8.8)$ & $10(17.5)$ & $3(5.3)$ \\
\hline HIC1 & $2(3.5)$ & $1(1.8)$ & $9(15.8)$ & $5(8.8)$ & $1(1.8)$ & $2(3.5)$ \\
\hline CHFR & $5(8.8)$ & $0(0.0)$ & $12(21.0)$ & $9(15.8)$ & $4(7.0)$ & $2(3.5)$ \\
\hline BRCA1 & $1(1.8)$ & $1(1.8)$ & $6(10.5)$ & $3(5.3)$ & $9(15.8)$ & $6(10.5)$ \\
\hline CASP8 & $1(1.8)$ & $0(0.0)$ & $2(3.5)$ & $1(1.8)$ & $8(14.0)$ & $5(8.8)$ \\
\hline CDKN1B & $1(1.8)$ & $0(0.0)$ & $7(12.3)$ & $3(5.3)$ & $5(8.8)$ & $5(8.8)$ \\
\hline PTEN & $1(1.8)$ & $0(0.0)$ & $13(22.8)$ & $6(10.5)$ & $6(10.5)$ & $3(5.3)$ \\
\hline BRCA2 & $1(1.8)$ & $0(0.0)$ & $7(12.3)$ & $4(7.0)$ & $5(8.8)$ & $2(3.5)$ \\
\hline CD44 & $3(5.3)$ & $1(1.8)$ & $8(14.0)$ & $1(1.8)$ & $8(14.0)$ & $8(14.0)$ \\
\hline RASSF1 & $2(3.5)$ & $2(3.5)$ & $2(3.5)$ & $3(5.3)$ & $18(31.6)$ & $10(17.5)$ \\
\hline DAPK1 & $9(15.8)$ & $3(5.3)$ & $6(10.5)$ & $5(8.8)$ & $3(5.3)$ & $4(7.0)$ \\
\hline VHL & $0(0.0)$ & $1(1.8)$ & $6(10.5)$ & $7(12.3)$ & $8(14.0)$ & $5(8.8)$ \\
\hline ESR1 & $10(17.5)$ & $7(12.3)$ & $2(3.5)$ & $2(3.5)$ & $5(8.8)$ & $5(8.8)$ \\
\hline TP73 & $3(5.3)$ & $4(7.0)$ & $4(7.0)$ & $3(5.3)$ & $4(7.0)$ & $3(5.3)$ \\
\hline FHIT & $3(5.3)$ & $0(0.0)$ & $4(7.0)$ & $3(5.3)$ & $12(21.0)$ & $3(5.3)$ \\
\hline IGSF4 & $5(8.8)$ & $5(8.8)$ & $6(10.5)$ & $8(14.0)$ & $4(7.0)$ & $2(3.5)$ \\
\hline CDH13 & $15(26.3)$ & $12(21.0)$ & $2(3.5)$ & $0(0.0)$ & $6(10.5)$ & $5(8.8)$ \\
\hline GSTP1 & $5(8.8)$ & $6(10.5)$ & $13(22.8)$ & $11(19.3)$ & $7(12.3)$ & $5(8.8)$ \\
\hline
\end{tabular}

Many associations between particular deletions and/or particular duplications were found in both tissues $(\mathrm{p}=0.002$ and $\mathrm{p}<0.001$, respectively, Spearman's test of correlation, BenjaminiHochberg procedure for multiple testing). However these changes were more common in cancer tissue than in normal laryngeal tissue $(\mathrm{p}<0.001, \mathrm{p}=0.015$, respectively, Fisher's test of independence). In particular, deletions in the chromosomal locus of the MLH1 and FHIT genes were significantly more frequent $(p=0.032$ and $p=0.024$, respectively, Fisher's test of independence).

A very strong association was found between duplication at the locus of the $C D K N 1 B$ gene (p27) and hypermethylation of the PTEN gene $\left(\mathrm{p}=3.782 \times 10^{-9}\right.$, Fisher's test of independence). Strong associations were also found between hypermethylation of the GSTP1 gene and deletion at the locus of the GSTP1 gene ( $\mathrm{p}=0.0001841$, Fisher's test of independence) and between deletion at CD44 in tumor cells and deletion at ESR1 in normal laryngeal cells ( $p=0.0008326$, Fisher's test of independence).

\section{Analysis of the association between clinical data and epigenetic alterations}

Lower values of both disease stage and tumor size (T) were associated with a higher than average number of deletions in tumor cells ( $p=0.01, p=0.021$, respectively, Kruskal-Wallis test). The cancers without deletions have on average a higher stage number and $\mathrm{T}$ than those with at least one deletion ( $\mathrm{p}=0.001$ and $\mathrm{p}=0.005$, Mantel-Haenszel test for linear association).

Metastases were associated with a high number of deletions in cancer cells ( $p=0.020$, Mann-Whitney test). The patients with at least 3 deletions in the laryngeal tumor had a higher rate of metastases ( $p=0.007$, Cox-Mantel test). In particular, an association between metastases and deletion at the FHIT locus in tumor cells was observed ( $\mathrm{p}=0.009$, Cox-Mantel test). The risk of metastasis increases as the number of hypermethylated genes in normal laryngeal cells increases ( $\mathrm{p}=0.014$, Wald's test). In particular, those who have at least 3 hypermethylated sites in normal laryngeal cells are more likely to develop metastasis ( $p=0.006$, Cox-Mantel test).

Recurrences were associated with a low number of hypermethylated genes and a low number of duplications in laryngeal cancers $(\mathrm{p}=0.013$ and $\mathrm{p}=0.014$, respectively, MannWhitney test). The risk of recurrence decreases as the number of duplications in tumor cells increases $(p=0.006$, Fisher's exact test; $p=0.021$, Wald's test). Patients, who have at least 3 duplications in tumor cells are significantly less likely to have a recurrence ( $\mathrm{p}=0.006$, Cox-Mantel test). In particular, those with duplications at CHFR and PTEN in tumor cells are less likely to suffer recurrence ( $\mathrm{p}=0.019$ and $\mathrm{p}=0.015$, respectively).

\section{Discussion}

We analysed promotor hypermethylation status in a homogeneous set of 57 primary LSCC using the MS-MLPA method and we have compared results to our others results obtained using MS-PCR method from a group of 72 patients with LSCC [9]. We observed a significantly higher frequency of gene methylation in cancer compared to normal tissues in the MS-MLPA and MS-PCR study [9]. The lack of hypermethylated genes in $10.5 \%$ of LSCCs (six tumours) in the MS-MLPA study may suggest the existence of hypermethylation of others genes or another mechanism of cancer development (the theory of the complex development of LSCC) [10,11].

In our MS-MLPA study, hypermethylation occurred most commonly at CDKN2B ( 15 ) gene in both tissues and tended to appear simultaneously. This observation confirms our results 


\section{Global Journal of Otolaryngology}

from the MS-PCR study, in which the hypermethylation of CDKN2B (p15) gene was correlated with high smoking packyears index [9]. Wong et al. found a high frequency of p15 gene methylation in primary HNSCC and in histologically-normal surgical margin epithelia of HNSCC in alcohol drinking and tobacco smoking patients [12]. All the patients from our study group were smokers and nearly all had a history of alcohol drinking. Furthermore, a high level of p15 and p16 genes methylation in the plasma of patients presented by Wong et al., suggests the possibility of using this change as a marker of early HNSCC detection in drinking and smoking patients [12].

In our study, hypermethylation of TIMP3 was significantly more common in cancer tissue than in healthy tissue. Aberrant methylation of CDKN2B and TIMP3 was frequent in laryngeal papillomas, head and neck cancers, as described in [11-13].

We observed that in cancer tissues, hypermethylation of the promotor region of particular genes tends to be associated with hypermethylation of other genes, rather than other genetic changes (duplications, deletions). For example hypermethylation of the following genes: FHIT, MLH1, IGSF4 and CD44, may well be strongly associated with each other. However, due to the relatively low rate of hypermethylation more data is required to investigate this phenomenon and the possible consequences.

Although many associations between particular deletions or/and particular duplications were found in both tissues. However, the associations between changes in tumor cells are stronger. In particular, deletions in the chromosomal locus of the MLH1 and FHIT genes were significantly more common in LSCC. Different genetic and epigenetic changes of MLH1 and FHIT genes in HNSCC are described in [11, 14-16]. In the other study performed by our group, more frequently loss of heterozygosity (LOH) than hypermethylation of MLH1 gene was observed [17]. LOH in MLH1 gene was correlated with higher grade [16].

We found a strong association between duplication at the locus of the CDKN1B gene (p27) and hypermethylation of the PTEN gene. It was suggested that PTEN may correlate with the activity of p27 $[18,19]$. Using an immunohistochemistry study of LSCC patients, Fan et al. found an association between lack of p27 expression and advanced clinical stage, lymph node involvement, and distant metastases [20]. Also, other authors have confirmed the correlation between low p27 levels and a poor prognosis in laryngeal cancer [21,22].

We observed associations between hypermethylation of the GSTP1 gene and deletion at the locus of the GSTP1 gene and between deletion at CD44 gene in tumor cells and deletion at ESR1 gene in normal laryngeal cells. Frequent hypermethylation of the GSTP1 gene in our MS-PCR study and in laryngeal cancer cell lines has been described in $[9,23,24]$. Aberrant methylation of ESR1 gene was found to be a predictor of late stage LSCC in a study performed by Stephen et al. using MS-MLPA [25]. It is suggested that CD44 expression is associated with a poor prognosis in pharyngolaryngeal cancer patients [26]. A study performed by Allegra et al. showed that determination of salivary CD44 levels can be used as a prognostic test in laryngeal carcinomas [27].

Stephen et al. studied hypermethylation of chosen genes in 79 primary LSCCs in 45 Caucasian Americans and 34 other patients using MS-MLPA [25]. The authors found that CDH13, RARB, GSTP1, TP53, APC, CHFR, DAPK1, CDKN2A and ESR1 genes were most frequently hypermethylated. Chen et al. using MS-MLPA method identified RARB, APC, CHFR as frequent hypermethylated sites in primary HNSCCs [28]. Lopez at al. analysed 53 primary laryngeal squamous cell carcinomas and found hypemethylation of RARB, APC, CHFR, DAPK1, CDKN2B to be frequent epigenetic events [29].

Our MS-MLPA study showed more frequently hypremethylation of ESR1 and CDH13, TIMP3, RARB, whereas the MS-PCR study: hipermethylation of GSTP1, DAPK1, DCC, MGMT, CDH1 [9]. Differences in hypermethylation sites may result from the different size of study groups, set of genes applied or different ethnic origins. In our MS-MLPA study there was a significant positive correlation between 1) the number of deletions and the number of duplications in tumors; 2) the number of deletions and the number of duplications in normal laryngeal tissues. The level of associations between various deletions seems to be higher in tumor cells than in healthy cells. This may indicate that deletions are a form of genetic instability and play an important role in the development of cancer. The following genes seem likely to be important in defining such genetic instability as they appear most often (CD44, RASSF1, RARB, FHIT, ESR1, CASP8).

In order to investigate the possibility of there being individuals with genetic instability, we looked at the distribution of the number of changes (hypermethylation, deletion and duplication in tumor and normal tissue) an individual has. All of these distributions are right skewed, in particular the distributions of the number of deletions in normal laryngeal and tumor cells. This may indicate that some individuals are affected by genetic instability. These observations are in agreement with previous results of research on genetic instability in LSCC [10,16,30]. In previously performed studies using MS-PCR method we selected three genes (DAPK1, CDH1, MGMT) and one MINT (methylated in tumors) sequence (MINT2), which hypermethylation can serve as markers of epigenetic instability [9].

We observed that lower values of the disease stage and tumor size ( $\mathrm{T}$ ) are associated with a higher average number of deletions in the tumor. In our studies, the occurrence of metastases was associated with the presence of at least 3 deletions in tumor cells or at least 3 hypermethylated genes in normal laryngeal cells. Deletion at the FHIT locus in tumor cells seems strongly associated with the occurrence of metastases ( $p=0.009$, CoxMantel test). This result is similar to those obtained by other authors, who reported deletion of the FHIT locus in $40-60 \%$ of tumors and cell lines in HNSCC [31-34]. Tai et al. found a loss of FHIT expression in 52 of the 80 study patients with HNSCC (65\%) [31]. Patients with tumors without FHIT expression had 


\section{Global Journal of Otolaryngology}

a worse 5-year survival record. Since the number of cases of metastasis observed in our study is low, more data is needed on the relation between metastasis and these changes.

LSCC is associated with the risk of recurrence and a second independent cancer of the respiratory system (mostly lung cancer) or cancer of the head and neck, which is mainly associated with exposure to the same carcinogenic agents before and after diagnosis (the theory of field carcinogenesis field cancerization). The risk of patients with laryngeal cancer developing a second primary tumor is approximately $10-30 \%$ $[3,35,36]$. A second outbreak of cancer in the same location, as well as advanced LSCC, is associated with a worse prognosis [29]. We found that patients with LSCC who had duplications at CHFR and PTEN in tumor cells were less likely to suffer recurrence. CHFR is a mitotic checkpoint protein that delays entry into mitosis in response to stress. CHFR is one of several proteins, which regulate the process of mitosis and are crucial for the maintenance of genomic stability. Shinde et al. showed in their study that PTEN plays an important role in the functioning of CHFR [38].

\section{Conclusion}

The results of our study confirm involvement of both epigenetic and genetic events in laryngeal cancer development. Further research using larger study groups, as well as more numerous set of genes, are necessary.

\section{References}

1. Clayman GL, Lippman SM, Laramore GF (2000) Neoplasms of the head and neck. Cancer medicine, $5^{\text {th }}$ edn. BC Becker Inc, New York (section 27), USA.

2. http://www.onkologia.org.pl/doc/Nowotwory2008.pdf (access 0710-2016).

3. Wierzbicka M, Szyfter W, Bien S, Maciejewski B, Skladowski K, et al. (2006) Diagnostic and therapeutic recommendations for selected neoplasm of the head and neck. Laryngeal carcinoma Contemporary Oncology 5:195-201.

4. Coupland VH, Chapman P, Linklater KM, Sehgal A, Møller H, et al (2009) Trends in the epidemiology of larynx and lung cancer in southeast England, 1985-2004. British Journal of Cancer 100(1): 167-169.

5. Sas Korczynska B, Korzeniowski S, Skolyszewski J (2003) Cancer of the larynx in females. Cancer Radiotherapie 7(6): 380-385.

6. Bien S, Kaminski B, Zylka S, Mezyk R, Piasta Z (2008) Evolution of the epidemiology and clinical characteristics of larynx and hypopharynx carcinoma in Poland from 1991 to 2001. European Archives of Otorhinolaryngology 265(Suppl 1): S39-S46.

7. de Freitas Cordeiro-Silva M, Stur E, Agostini LP, de Podestá JR, de Oliveira JC, et al. (2012) Promoter hypermethylation in primary squamous cell carcinoma of the oral cavity and oropharynx a study of a Brazilian cohort. Mol Biol Rep 39(12): 10111-10119.

8. Stembalska A, Leszczynski P, Gil J et al.(2014) Global DNA methylation status in laryngeal cancer. Head Neck 36: 419-424.

9. Stembalska A (2011) Analysis of chosen epigenetic events in LSCC [Analiza wybranych zmian epigenetycznych w płaskonabłonkowym raku krtani]. Wroclaw 2011 [in Polish]. ISBN 987-83-7055-556-6.
10. Stembalska A (2002) Loss of heterozygosity of chosen genes and genetic instability in laryngeal squamous cell carcinoma. [PhD thesis, in Polish]. Wroclaw, 2002, unpublished data.

11. Demokan S, Dalay N (2011) Role of DNA methylation in head and neck cancer. Clin Epigenetics 2(2): 123-150.

12. Wong TS, Man MW, Lam AK, Wei WI, Kwong YL, et al. (2003) The study of p16 and p15 gene methylation in head and neck squamous cell carcinoma and their quantitative evaluation in plasma by real-time PCR. Eur J Cancer 39(13): 1881-1887.

13. Stephen JK1, Chen KM, Shah V, Schweitzer VG, Gardner G, et al. (2010) Consistent DNA hypermethylation patterns in laryngeal papillomas. Int J Head Neck Surg 1(2): 69-77.

14. Paluszczak J, Misiak P, Wierzbicka M, Woźniak A, Baer-Dubowska W (2011) Frequent hypermethylation of DAPK, RARbeta, MGMT RASSF1A and FHIT in laryngeal squamous cell carcinomas and adjacent normal mucosa. Oral Oncol 47(2): 104-107.

15. Pierini S, Jordanov SH, Mitkova AV, Chalakov IJ, Melnicharov MB, et al. (2014) Promoter hypermethylation of CDKN2A, MGMT, MLH1, and DAPK genes in laryngeal squamous cell carcinoma and their associations with clinical profiles of the patients. Head Neck 36(8): 1103-1108.

16. Sasiadek MM, Smigiel R, Stembalska A, Ramsey D, Blin N (2006) Cyclin D1 and MLH1 levels in laryngeal cancer are linked to chromosomal imbalance. Anticancer Res 26(68): 4597-4601.

17. Smigiel R, Stembalska-Kozlowska A, Mirghomizadeh F, Krecicki T, Zatonski T, et al. (2004) Correlation among loss of heterozygosity promotor methylation and protein expression of MLH1 in larynx cancer. Oncol Rep 11(13): 707-710.

18. Kirla RM, Haapasalo HK, Kalimo H, Salminen EK (2003) Low Expression of p27 Indicates a Poor Prognosis in Patients with HighGrade Astrocytomas. Cancer 97(3): 644-648.

19. Li D, Sun H (1998) PTEN/MMAC1/TEP1 suppresses the tumorigenicity and induces G1 cell cycle arrest in human glioblastoma cells. Proc Nat Acad Sci USA 95(26): 15406-15411.

20. Fan GK, Fujieda S, Sunaga H, Tsuzuki H, Ito N, et al. (1999) Expression of protein p27 is associated with progression and prognosis in laryngeal cancer. Laryngoscope 109(5): 815-8220.

21. Qin XL, Guo QH, Zheng H, Zheng Y (2000) p27 protein expression and its significance in human laryngeal carcinoma. Lin Chuang Er Bi Yan Hou Ke Za Zhi 14(12): 533-535.

22. Tamura N, Dong Y, Sui L, Tai Y, Sugimoto K, et al. (2001) Cyclindependent kinase inhibitor p27 is related to cell proliferation and prognosis in laryngeal squamous cell carcinomas. J Laryngol Otol 115(5): 400-406.

23. Paluszczak J, Krajka-Kuzniak V, Malecka Z, Jarmuż M, Kostrzewska Poczekaj M, et al. (2011) Frequent gene hypermethylation in laryngeal cancer cell lines and the resistance to demethylation induction by plant polyphenols. Toxicol In Vitro 25(1): 213-221.

24. Matthias C, Bockmühl U, Jahnke V, Harries LW, Wolf CR, Jones PW et al. (1998) The glutathione S-transferase GSTP1 polymorphism: effects on susceptibility to oral/pharyngeal and laryngeal carcinomas Pharmacogenetics 8(1): 1-6.

25. Stephen JK, Chen KM, Shah V, Veena Shah, Shaleta Havard, et al. (2010) DNA hypermethylation markers of poor outcome in laryngeal cancer Clin Epigenetics 1(1-2): 61-69.

26. Chai L, Liu H, Zhang Z, Wang Q, Zhou S et al. (2014) predictive CD44 expression is of poor prognosis in pharyngolaryngeal cancer: systematic review and meta-analysis. Tohoku J Exp Med ] 232(1): 9-19. 
27. Allegra E, Trapasso S, La Boria A, Aragona T, Pisani D et al. (2014) Prognostic role of salivary CD44sol levels in the follow-up of laryngeal carcinomas. J Oral Pathol Med 43(4): 276-281.

28. Chen K, Sawhney R, Khan M, Benninger MS, Hou Z, et al. (2007) Methylation of multiple genes as diagnostic and therapeutic markers in primary head and neck squamous cell carcinoma. Arch Otolaryngol Head Neck Surg 133(11): 1131-1138.

29. López F, Sampedro T, Llorente JL, Domínguez F, Hermsen M, et al (2014) Utility of MS-MLPA in DNA methylation profiling in primary laryngeal squamous cell carcinoma. Oral Oncol 50(4): 291-297.

30. Demokan S, Suoglu Y, Demir D, Gozeler M, Dalay N. et al. (2006) Microsatellite instability and methylation of the DNA mismatch repair genes in head and neck cancer. Ann Oncol 17(6): 995-999.

31. Tai SK, Lee JI, Ang KK, El-Naggar AK, Hassan KA, et al. (2004) Loss of FHIT expression in Head and Neck Squamous Cell Carcinoma and its potential clinical implication. Clin Cancer Res 10(16): 5554-5557.

32. Tanimoto K, Hayashi S, Tsuchiya E, Y Tokuchi, Y Kobayashi, et al (2000) Abnormalities of the FHIT gene in human oral carcinogenesis. Br J Cancer 82(4): 838 -843.
33. Kisielewski AE, Xiao GH, Liu SC, Klein-Szanto AJ, Novara M, et al (1998) Analysis of the FHIT gene and its product in squamous cell carcinomas of the head and neck. Oncogene 17(1): 83-91.

34. Chang KW, Kao SY, Tzeng RJ, Liu CJ, Cheng AJ, et al. (2002) Multiple molecular alterations of FHIT in betel-associated oral carcinoma. Journal of Pathology 196(3): 300-306.

35. Giefing M, Rydzanicz M, Szukala K, Wozniak A, Wierzbicka M, et al. (2005) Second primary tumors (SPT) of head and neck: distinguishing of "true" SPT from micrometastasis by LOH analysis of selected chromosome regions. Neoplasma 52(5): 374-380.

36. Rusin P, Markiewicz L, Majsterek I (2008) Genetic predeterminations of head and neck cancer. Postepy Hig Med Dosw (Online) 62: 490-501.

37. Scolnick DM, Halazonetis TD (2000) Nature 406: 430-435.

38. Shinde SR, Gangula NR, Sridhar K, Vimal P, Subbareddy M (2013) TOPK and PTEN participate in CHFR mediated mitotic checkpoint. Cell Signal 25(12): 2511-2517.

\section{Your next submission with Juniper Publishers will reach you the below assets}

- Quality Editorial service

- Swift Peer Review

- Reprints availability

- E-prints Service

- Manuscript Podcast for convenient understanding

- Global attainment for your research

- Manuscript accessibility in different formats

( Pdf, E-pub, Full Text, Audio)

- Unceasing customer service

Track the below URL for one-step submission https://juniperpublishers.com/online-submission.php 